\title{
Efficacy and safety of everolimus in Chinese metastatic HR positive, HER2 negative breast cancer patients: a real-world retrospective study
}

\author{
Chengcheng Gong ${ }^{1, *}$, Yannan Zhao ${ }^{1, *}$, Biyun Wang ${ }^{1}$, Xichun Hu${ }^{1}$, Zhonghua Wang ${ }^{1}$, \\ Jian Zhang ${ }^{1}$ and Sheng Zhang ${ }^{1}$ \\ ${ }^{1}$ Department of Medical Oncology, Fudan University Shanghai Cancer Center, Department of Oncology, Shanghai Medical \\ College, Fudan University, Shanghai, 200032, China \\ * These authors have contributed equally to this work \\ Correspondence to: Biyun Wang, email: pro_wangbiyun@163.com
}

Xichun Hu, email: xchu2009@hotmail.com

Keywords: everolimus, endocrine therapy, metastatic breast cancer, real-world study

Received: November 17.2016 Accepted: February 15,2017 Published: March 17, 2017

Copyright: Gong et al. This is an open-access article distributed under the terms of the Creative Commons Attribution License 3.0 (CC BY 3.0), which permits unrestricted use, distribution, and reproduction in any medium, provided the original author and source are credited.

\section{ABSTRACT}

Background: Everolimus combined with endocrine therapy has been proved to be effective among postmenopausal women with hormone receptor-positive human epidermal growth factor receptor-2 negative (HR+/HER2-) metastatic breast cancer (MBC). We aimed to evaluate the efficacy and safety of everolimus plus endocrine therapy in Chinese real-world practice for the first time, and investigate factors associated with efficacy.

Methods: Seventy-five HR+/HER2- MBC patients were included in this retrospective study who received everolimus plus endocrine therapy after progression on prior endocrine therapy in Fudan University Shanghai Cancer Center (FUSCC) between June 2013 and February 2016. Main outcome measures are progression free survival (PFS), overall survival (OS), objective response rate (ORR), clinical benefit rate (CBR) and safety profile.

Results: After a median follow up of 10.3 (range: 2.1-32.2) months, median PFS was 5.9 months (95\%CI 4.6-7.2), and median OS was not reached. The CBR was $38.8 \%(95 \% C I, 26.8-50.8)$ and ORR was $9.0 \%$ (95\%CI, 2.0-16.0). Most common allgrade adverse events were stomatitis $(57.1 \%)$, fatigue $(25.7 \%)$, infection $(24.3 \%)$ and hyperglycemia ( $21.4 \%)$. The most common $\geq 3$ grade adverse events were stomatitis $(9.3 \%)$ and thrombocytopenia (5.7\%). No treatment-related death was documented during and one month after the drug administration.

Conclusions: The combination of everolimus and endocrine therapy proved to be effective in Chinese population. The safety profiles were similar to previous studies but incidences were lower. In conclusion, everolimus combined with endocrine therapy provides a reasonable option for Chinese HR+/HER2- metastatic breast cancer patients.

\section{INTRODUCTION}

Breast cancer is one of the most prevalent malignancy and the leading causes of cancer morality in women worldwide and in China [1,2]. Endocrine therapy (ET) is the cornerstone of the treatment for hormonereceptor positive $(\mathrm{HR}+)$ breast cancer $(\mathrm{BC})$, accounting for approximately $70 \%$ of breast cancer [3-5]. However, patients receiving endocrine therapy eventually experience disease progression, either fail to respond in the first evaluation or progress after initial response [6]. Once the patients progress on initial endocrine therapy, sequential lines of ET offer limited clinical benefit. Emerging studies have been done to explain the mechanism behind endocrine resistance in order to identify new therapeutic strategies. The activation of phosphatidylinositol 3-kinase 
(PI3K)/Akt/ mammalian target of rapamycin (mTOR) pathway proved to be one of the key factors of endocrine resistance $[7,8]$. Preclinical studies indicate that the inhibition of mTOR signaling has antitumor effect and can restore sensitivity to fulvestrant, letrozole, and tamoxifen in breast cancer cells [9-11].

Everolimus (Afinitor, Novartis), an orally selective inhibitor of mTORC1, has been shown to enhance the antitumor effect of endocrine therapy in breast cancers [12-15] . BOLERO-2 (Breast cancer trial of OraL EveROlimus- 2), a phase III study, demonstrated that the addition of everolimus to exemestane significantly prolonged the PFS from 3.2 months to 7.8 months (from 4.1 to 11.0 months by central review) in postmenopausal HR+/HER2- advanced breast cancer patients refractory to nonsteroidal aromatase inhibitor (NSAI) [16, 17]. Based on the impressive improvement on PFS, everolimus in combination with exemestane was approved for the treatment of postmenopausal HR+/HER2- advanced breast cancer patients recurring or progressing on prior NSAIs in the USA and European Union.

In China, however, the indication of everolimus in advanced breast cancer hasn't been approved, thus there is limited data about efficacy and safety of everolimus in Chinese breast cancer patients. Our study aimed to address this knowledge gap by providing first-hand evidence of the real-world efficacy and safety profile of everolimus in Chinese metastatic HR+/HER2- breast cancer patients.

\section{MATERIALS AND METHODS}

\section{Patients}

Patients with HR+/HER2- advanced breast cancer who failed on previous endocrine therapy and were treated with everolimus plus endocrine therapy in any line in metastatic setting from June 2013 to February 2016 in Fudan University Shanghai Cancer Center (FUSCC) were included. Data were retrospectively obtained from patients' medical history. Everolimus combined with chemotherapy or target therapy were not discussed in this study. Demographic and clinical characteristics were evaluated in all patients. This study was approved by Fudan University Shanghai Cancer Center.

\section{Treatment}

Everolimus was usually initiated at the dose of $10 \mathrm{mg}$ or in some instances at $5 \mathrm{mg}$ daily, according to patients' tolerance and request. The treatment could be interrupted, reduced to $5 \mathrm{mg}$ once daily, or permanently discontinued due to its adverse events. The endocrine therapy combined with everolimus was up to doctors' choice based on prior endocrine treatments.

\section{Efficacy and safety}

Efficacy was assessed by progression free survival (PFS), overall survival (OS), objective response rate (ORR), and clinical benefit rate (CBR). PFS was defined as time from initiation of everolimus to disease progression or death. OS was estimated from the date of treatment initiation to death of any cause or last follow-up. CBR was defined as the percentage of complete response (CR), partial response (PR) or stable disease (SD) for $\geq 24$ weeks and ORR was considered as the percentage of CRs and PRs. Efficacy was evaluated by CT, MRI, bone scan and physical examination every 2-3 months until disease progression. Tumor responses were confirmed by researcher according to Response Evaluation Criteria in Solid Tumors (RECIST) 1.1 criteria.

Adverse events (AEs) were determined retrospectively based on patients' medical records and laboratory tests results. Nonhematologic AEs were also evaluated by telephone follow-up. Patients without posttreatment safety evaluation were excluded from safety population. AEs were assessed according to the National Cancer Institute Common Terminology Criteria for Adverse Events version 4.0.

\section{Statistical analysis}

Quantitative data are presented as median (range) or number of patients (percentage).

PFS and OS were estimated by the Kaplan- Meier method and the hazard ratios (HRs) and corresponding 95\% confidence intervals (CIs) were estimated using the Cox proportional harzard model.

Exploratory univariate analyses were performed with the log- rank test using the following variables: age, disease-free interval (DFI), number of metastatic sites (1-2 vs $\geq 3$ ), visceral metastases, liver/lung/bone metastases, lines of previous chemotherapy and endocrine treatment ( $0-1$ vs $\geq 2$ ), hormone resistance (primary vs secondary), the occurrence of symptomatic stomatitis, and combinational endocrine treatment. Primary endocrine resistance was defined as: a relapse during the first 2 years of adjuvant ET, or progress within first 6 months of first-line ET for MBC. Secondary endocrine resistance was defined as: a relapse during adjuvant ET but after the first 2 years, or a relapse within 12 months of completing adjuvant ET, or progress $\geq 6$ months after initiating ET for MBC [18]. Symptomatic stomatitis was defined as showing symptoms of stomatitis, such as pain and functional impact.

Cox multivariate models were performed based on the univariate analyses results. All expressed $P$ values and CIs were two tailed. The significance level of statistical tests was set at $\mathrm{p}<0.05$. CBR and ORR were calculated with their $95 \% \mathrm{CI}$. The safety population included patients 
who had post-treatment safety evaluation. AEs were summarized using percentages and frequency counts. The Kaplan-Meier method was used to evaluate time-to-onset of AEs of clinical interest. All statistical analyses were conducted using SPSS IBM® version 22.

\section{RESULTS}

\section{Patients and treatment}

A total of $75 \mathrm{HR}+/$ HER2- metastatic breast cancer patients treated with everolimus plus endocrine therapy between June 2013 and February 2016 in FUSCC were included. Clinicopathological characteristics at the initiation of everolimus are shown in Table 1. The median age of the patients was 53 (range 24-73) years. Most patients were in postmenopausal status (80.0\%). 13 $(17.3 \%)$ premenopausal women were required to receive medical ovarian suppression during everolimus treatment. 5 patients were de novo stage IV breast cancer $(6.7 \%)$. All patients were histologically confirmed HR+/HER2advanced breast cancer patients, except that 5 patients' HER-2 data were not available. More than half of the patients had $\geq 3$ metastatic sites. The most common sites of metastases were bone (69.3\%), lung (57.3\%) and liver (46.7\%). Most patients had visceral involvement (82.7\%).

All patients had received previous endocrine therapy, including NSAIs (90.7\%), tamoxifen (66.7\%), exemestane $(41.3 \%)$, and fulvestrant $(38.7 \%)$. The most recent therapy before everolimus was NSAIs (50.6\%). By the definitions previously described, primary resistance occurred in $24 \%$ of the patients while $73.3 \%$ had secondary resistance. $77.3 \%$ of the patients had received chemotherapy in metastatic settings.

At the cutoff time (May 25th, 2016), the combination was ongoing for six patients. Reasons for treatment discontinuation were disease progression $(62.3 \%)$, intolerable toxicity $(20.3 \%)$, patients' choice (14.4\%) and loss of follow up (2.9\%). Median duration of everolimus treatment was 15.1 (range 1-131.6) weeks. Oncologists' choices of concomitant endocrine therapy were as follow: exemestane (72\%), NSAIs (14.7\%), tamoxifen $(8.0 \%)$, and fulvestrant $(5.3 \%)$.

\section{Efficacy}

At a median follow up of 10.3 (range: 2.1-32.2) months, median PFS was 5.9 months (95\%CI 4.6-7.2). With 22 (29.3\%) patients died, overall survival data were immature at the time of the analysis. The Kaplan-Meier PFS is shown in Figure 1.

Tumor responses were shown in Table 2. 8 patients' responses were unable to evaluate. Among 67 patients with evaluable disease, 6 patients $(9.0 \%)$ achieved PR, 44 patients $(65.7 \%)$ had SD, and 17 patients $(25.4 \%)$ reported PD after the combinational treatment of everolimus and endocrine therapy. This resulted in a CBR of $38.8 \%(95 \%$ CI, 26.8-50.8) and an ORR of 9.0\% (95\% CI, 2.0-16.0). Univariate analysis indicated that PFS was significantly longer in patients $\geq 45$ years old than in those $<45$ years old (HR, $0.53,95 \%$ CI $0.30-0.93, p=0.027$ ), in patients with symptomatic stomatitis during treatment than in those without (HR,0.57, 95\%CI 0.34-0.98, $p=0.042)$ and in patients without liver metastasis than those with liver metastasis (HR, 2.06, 95\%CI 1.24-3.44, $p=0.006$ ) (Table $3 \&$ Figure 2). Cox multivariate models were derived from the univariate analysis results. A significant association was observed by Cox multivariate analysis between PFS and the presence of liver metastasis ( $\mathrm{HR}, 1.93 ; 95 \% \mathrm{CI}$ $1.13-3.28, p=0.016)$.

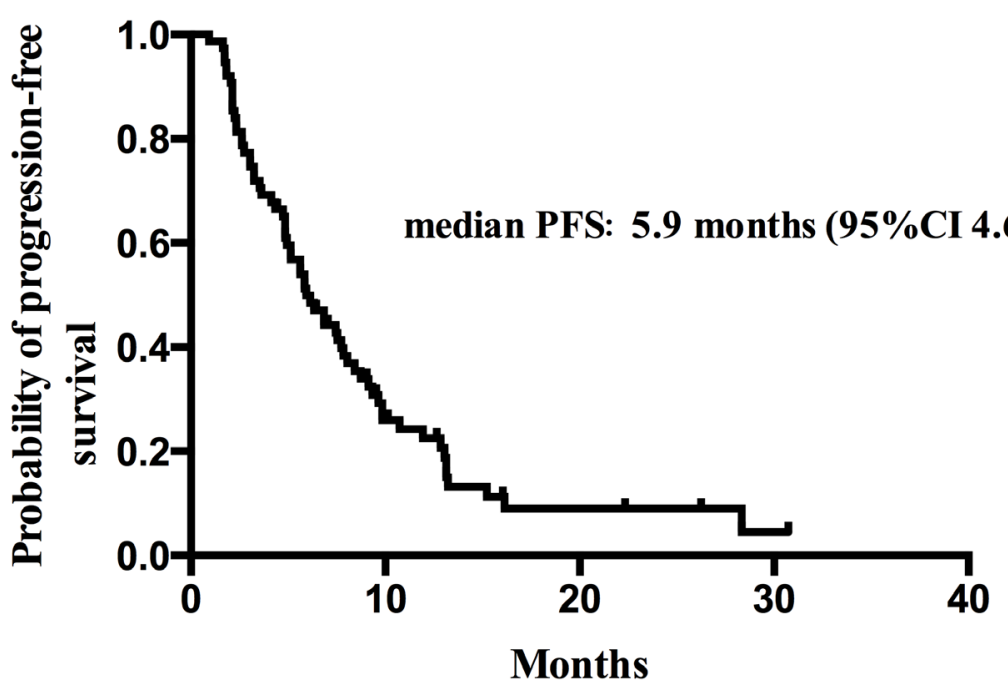

Figure 1: Kaplan-Meier estimates of progression-free survival of patients treated with everolimus and endocrine therapy. 
Table 1: Patients and tumor characteristics $(N=75)$.

\begin{tabular}{|c|c|c|}
\hline \multirow{2}{*}{ Characteristics } & \multicolumn{2}{|c|}{ Everolimus plus endocrine therapy } \\
\hline & No. & $\%$ \\
\hline \multicolumn{3}{|l|}{ Age (years) } \\
\hline Median & \multicolumn{2}{|c|}{53} \\
\hline Range & \multicolumn{2}{|c|}{$24-73$} \\
\hline \multicolumn{3}{|l|}{ Menopausal status } \\
\hline Postmenopausal & 60 & 80.0 \\
\hline Premenopausal & 13 & 17.3 \\
\hline Unknown & 2 & 2.7 \\
\hline \multicolumn{3}{|l|}{ Hormone receptor and HER-2 status } \\
\hline HR positive & 75 & 100 \\
\hline HER-2 negative* & 70 & 93.3 \\
\hline de novo stage IV breast cancer & 5 & 6.7 \\
\hline \multicolumn{3}{|l|}{ Disease-free interval (months) } \\
\hline$<12$ & 9 & 12 \\
\hline $12-24$ & 14 & 18.7 \\
\hline$>24$ & 47 & 62.7 \\
\hline \multicolumn{3}{|l|}{ No. of metastatic sites } \\
\hline 1 & 9 & 12 \\
\hline 2 & 21 & 28 \\
\hline$\geq 3$ & 45 & 60 \\
\hline \multicolumn{3}{|l|}{ Metastatic sites } \\
\hline Lung & 43 & 57.3 \\
\hline Liver & 35 & 46.7 \\
\hline Bone & 52 & 69.3 \\
\hline Visceral disease & 62 & 82.7 \\
\hline \multicolumn{3}{|l|}{ Lines of endocrine therapy } \\
\hline First line & 8 & 10.7 \\
\hline Second line & 31 & 41.3 \\
\hline Third or more line & 36 & 48 \\
\hline \multicolumn{3}{|l|}{ Previous endocrine therapy } \\
\hline Letrozole or anastrozole & 68 & 90.7 \\
\hline Tamoxifen & 50 & 66.7 \\
\hline Exemestane & 31 & 41.3 \\
\hline Fulvestrant & 29 & 38.7 \\
\hline \multicolumn{3}{|l|}{ The most recent endocrine therapy } \\
\hline Letrozole or anastrozole & 38 & 50.6 \\
\hline Fluvestrant & 19 & 25.3 \\
\hline Exemestane & 13 & 17.3 \\
\hline
\end{tabular}




\begin{tabular}{|l|c|c|}
\hline Tamoxifen & 5 & 6.7 \\
\hline Hormone resistance & 18 & 24 \\
\hline Primary endocrine resistance & 55 & 73.3 \\
\hline Secondary endocrine resistance & 2 & 2.7 \\
\hline Unable to determine & \multicolumn{2}{|c|}{} \\
\hline Previous chemotherapy & 17 & 22.7 \\
\hline (Neo)adjuvant therapy only & 58 & 77.3 \\
\hline Metastatic disease & 16 & 21.3 \\
\hline Lines of metastatic chemotherapy & 17 & 22.7 \\
\hline 1 & 25 & 33.3 \\
\hline 2 & & \\
\hline$\geq 3$ &
\end{tabular}

* 5 patients' HER-2 data were not available.

Table 2: Tumor responses $(N=67)$.

\begin{tabular}{|c|c|c|}
\hline Responses & No. of patients & \% \\
\hline CR & 0 & 0 \\
\hline PR & 6 & 9.0 \\
\hline SD & 44 & 65.7 \\
\hline PD & 17 & 25.4 \\
\hline ORR(\%) & & $9.0(95 \% \mathrm{CI}, 2.0-16.0)$ \\
\hline CBR $(\%)$ & & $38.8(95 \%$ CI $26.8-50.8)$ \\
\hline
\end{tabular}

Abbreviations: CR, complete response; PR, partial response; SD, stable disease; PD, progression disease; ORR, objective response rate; $\mathrm{CBR}$, clinical benefit rate

\section{Safety}

Safety analysis included 70 patients who had posttreatment safety evaluation after receiving the study treatment. Most frequent all-grade non-hematological side effects included stomatitis [Preferred terms of adverse events are used in this paper. The corresponding terminology used in CTCAE 4.0 are listed below. Stomatitis: mucositis oral (CTCAE 4.0). Noninfectious pneumonitis: pneumonitis. Thrombocytopenia: platelet count decreased. Leukopenia: white blood cell counts decreased. Hyperlipidemia includes cholesterol high and hypertriglyceridemia. Edema includes edema face, edema limbs and edema trunk. Rash includes rash pustular, rash acneiform, papulopustular rash and rash maculo-papular] (57.1\%), fatigue (25.7\%), infection (24.3\%), rash (18.6\%), edema $(14.3 \%)$, cough $(12.9 \%)$, diarrhea $(12.9 \%)$ and noninfectious pneumonitis (NIP) $(10.0 \%)$. Most common laboratory abnormities were hyperglycemia $(21.4 \%)$, alanine aminotransferase increased (18.6\%), aspartate aminotransferase increased (18.6\%), anemia (14.3\%), hyperlipidemia (10.0\%) and thrombocytopenia (10.0\%). Most events were grade 1 or 2 . The most common grade 3 events were stomatitis $(9.3 \%)$ and thrombocytopenia (5.7\%). No grade 4 events were observed. These findings are consistent with those from previous studies. No treatment-related death was documented during and one month after the drug administration. All adverse events are listed in Table 4.

Further analysis revealed that more than $40 \%$ of all stomatitis events were reported in the first 2 weeks (cumulative risk, 42.9\%). The median time of noninfectious pneumonitis onset was 13 weeks (cumulative risk, 10.9\%). The most common laboratory abnormity was hyperglycemia. $21.4 \%$ patients had hyperglycemia during study. The median time of onset was 8.6 weeks (cumulative risk 13.0\%). In most cases, the hyperglycemia was mild and controllable by oral hypoglycemic agent. One patient had grade 3 hyperglycemia and the dose of everolimus was reduced to $5 \mathrm{mg}$. Cumulative risk estimates for initial onset of stomatitis, noninfectious pneumonitis, and hyperglycemia were shown in Figure 3. 
Table 3: Exploratory analysis of factors to predict PFS of everolimus.

\begin{tabular}{|c|c|c|c|c|}
\hline Factors & PFS(months) & HRs & $95 \% \mathrm{CI}$ & $P$ value \\
\hline \multicolumn{5}{|l|}{ Age (years) ${ }^{\#}$} \\
\hline$\geq 45 N=55$ & 6.83 & \multirow{2}{*}{0.53} & \multirow{2}{*}{$0.30-0.93$} & \multirow{2}{*}{$0.027^{*}$} \\
\hline$<45 N=20$ & 5.57 & & & \\
\hline \multicolumn{5}{|l|}{ Menstruation status $^{+}$} \\
\hline Postmenopausal $N=60$ & 6.30 & \multirow{2}{*}{0.64} & \multirow{2}{*}{$0.34-1.21$} & \multirow{2}{*}{0.171} \\
\hline Premenopausal + OFS $N=13$ & 5.83 & & & \\
\hline \multicolumn{5}{|l|}{ DFI (months) } \\
\hline$>24 N=47$ & 5.90 & \multirow{2}{*}{0.87} & \multirow{2}{*}{$0.50-1.51$} & \multirow{2}{*}{0.872} \\
\hline$<24 N=23$ & 5.77 & & & \\
\hline \multicolumn{5}{|l|}{ No. of metastatic sites } \\
\hline $1-2 N=30$ & 6.30 & \multirow{2}{*}{0.94} & \multirow{2}{*}{$0.57-1.57$} & \multirow{2}{*}{0.820} \\
\hline$\geq 3 N=45$ & 5.83 & & & \\
\hline \multicolumn{5}{|l|}{ Visceral disease } \\
\hline Yes $N=62$ & 6.10 & \multirow{2}{*}{1.27} & \multirow{2}{*}{$0.64-2.51$} & \multirow{2}{*}{0.495} \\
\hline No $N=13$ & 5.90 & & & \\
\hline \multicolumn{5}{|l|}{ Liver metastasis $^{\#}$} \\
\hline Yes $N=35$ & 5.10 & \multirow{2}{*}{2.06} & \multirow{2}{*}{$1.24-3.44$} & \multirow{2}{*}{$0.006^{*}$} \\
\hline No $N=40$ & 7.70 & & & \\
\hline \multicolumn{5}{|l|}{ Lung metastasis } \\
\hline Yes $N=43$ & 6.83 & 082 & $050-135$ & 0430 \\
\hline No $N=32$ & 5.63 & 0.02 & $0.00-1.03$ & 0.450 \\
\hline Bone metastasis & & & & \\
\hline Yes $N=52$ & 5.57 & & & \\
\hline No $N=23$ & 9.07 & 1.03 & $0.94-2.09$ & 0.002 \\
\hline No. of previous metastatic chemo & & & & \\
\hline$\geq 2 N=42$ & 5.57 & 155 & 002962 & 0008 \\
\hline $0-1 N=33$ & 7.70 & 1.55 & $0.92-2.02$ & 0.098 \\
\hline No. of previous metastatic endocr & & & & \\
\hline$\geq 2 N=36$ & 5.90 & 103 & 062160 & 0021 \\
\hline $0-1 N=39$ & 5.77 & 1.03 & $0.02-1.09$ & 0.921 \\
\hline Hormone resistance $^{\#+}$ & & & & \\
\hline Primary Resistant $N=18$ & 5.13 & 121 & $0<6022$ & 0520 \\
\hline Secondary Resistant $N=55$ & 6.10 & 1.21 & $0.00-2.25$ & 0.532 \\
\hline Symptomatic stomatitis $^{\#}$ & & & & \\
\hline Yes $N=30$ & 7.80 & 057 & 024008 & $0012 *$ \\
\hline No $N=40$ & 4.77 & & & \\
\hline Combined endocrine therapy & & & & \\
\hline Exemestane $N=54$ & 6.77 & & & \\
\hline Tamoxifen $N=6$ & 5.77 & & & \\
\hline Anatozole $N=6$ & 4.77 & NA & NA & NA \\
\hline Letrozole $N=5$ & 3.23 & & & \\
\hline Fulvestrant $N=4$ & 3.0 & & & \\
\hline
\end{tabular}

Abbreviations: HR, hazard ratio, CI, confidence interval, OFS, ovarian function suppression, DFI, disease-free interval.

$* p<0.05$ is considered significant.

\# factors included in Cox multivariate models.

+ Missing data were not included in the analysis. 
Table 4: Adverse events $(N=70)$

\begin{tabular}{|c|c|c|c|}
\hline & Adverse Events & $\begin{array}{l}\text { All grades } \\
\qquad(\%)\end{array}$ & $\geq \underset{(\%)}{\operatorname{Grade} 3}$ \\
\hline \multirow[t]{12}{*}{ Non hematological events } & Stomatitis & 57.1 & 9.3 \\
\hline & Fatigue & 25.7 & 1.4 \\
\hline & Infection & 24.3 & 2.9 \\
\hline & Rash & 18.6 & 0 \\
\hline & Edema & 14.3 & 0 \\
\hline & Cough & 12.9 & 0 \\
\hline & Diarrhea & 12.9 & 1.4 \\
\hline & Noninfectious pneumonitis & 10.0 & 0 \\
\hline & Pyrexia & 10.0 & 0 \\
\hline & Anorexia & 7.1 & 0 \\
\hline & Hypertension & 7.1 & 2.9 \\
\hline & Weight loss & 5.7 & 0 \\
\hline \multirow[t]{4}{*}{ Biological events } & Hyperglycemia & 21.4 & 1.4 \\
\hline & ALT increased & 18.6 & 1.4 \\
\hline & AST increased & 18.6 & 1.4 \\
\hline & Hyperlipidemia* & 10.0 & 0 \\
\hline \multirow[t]{3}{*}{ Hematological events } & Anemia & 14.3 & 4.3 \\
\hline & Thrombocytopenia & 10.0 & 5.7 \\
\hline & Leukopenia & 5.7 & 0 \\
\hline
\end{tabular}

Abbreviations: ALT, alanine aminotransferase, AST, aspartate aminotransferase. *Includes hypercholesterolemia (5.7\%) and hypertriglyceridemia $(4.3 \%)$.

Everolimus was initially prescribed at the standard dose of $10 \mathrm{mg}$ daily in 54 patients $(77.1 \%)$ and at $5 \mathrm{mg}$ daily in 16 patients $(22.9 \%)$. In patients who initialed the treatment at $10 \mathrm{mg}, 11$ patients were reduced to 5 mg during the treatment. Among patients who began at $5 \mathrm{mg}$ daily, 4 patients increased to $10 \mathrm{mg}$ after the first few weeks while 12 patients remained at $5 \mathrm{mg}$ along the treatment (see Figure 4).
A

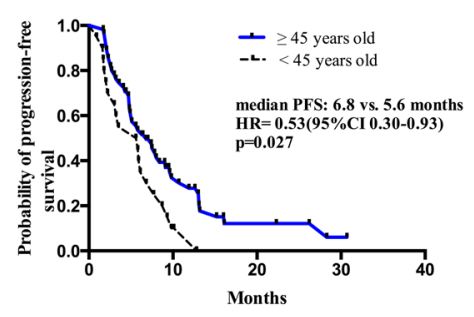

B

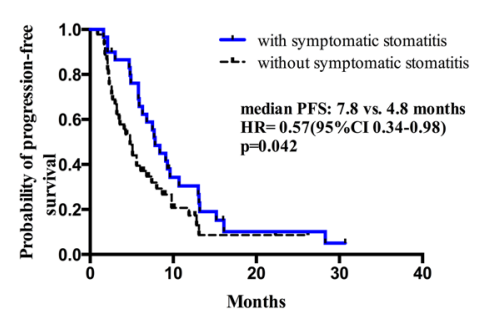

The most common AEs leading to dose interruptions/reductions in our study is stomatitis $(\mathrm{N}=$ $7)$, infection $(N=6)$, thrombocytopenia $(N=4)$, alanine/ aspartate aminotransferase increased $(N=3)$, rash $(N=2)$, edema $(N=2)$ and $\operatorname{NIP}(N=2)$. Treatment discontinuations because of AEs were $18.6 \%$ patients.

Figure 2: Kaplan-Meier curves for progression-free survival. For patients stratified by potential factors related with PFS. A. Age, B. Symptomatic stomatitis. C. Liver metastasis. Abbreviations: CI, confidence interval; PFS, progression-free survival. 
Table 5: Comparison with previous studies.

\begin{tabular}{|c|c|c|c|c|}
\hline \multirow{2}{*}{\multicolumn{2}{|c|}{ Parameters }} & \multirow{3}{*}{$\begin{array}{c}\text { FUSCC } \\
75\end{array}$} & \multirow{3}{*}{$\begin{array}{c}\text { BOLERO-2 }^{\text {a }} \\
485\end{array}$} & \multirow{3}{*}{$\begin{array}{c}\text { BOLERO-2 } \\
\text { Asian subgroup }^{b} \\
98\end{array}$} \\
\hline & & & & \\
\hline \multirow{2}{*}{ Number of patients } & Total & & & \\
\hline & Safety Population & 70 & 482 & 98 \\
\hline Age (years) & Median & 53 & 62 & 59.5 \\
\hline \multirow{2}{*}{$\begin{array}{l}\text { Exposure duration to } \\
\text { everolimus (weeks) }\end{array}$} & Median & 15.1 & 23.9 & 27.6 \\
\hline & Range & $1-131.6$ & $1-123.3$ & $2-123.3$ \\
\hline \multirow{2}{*}{ PFS (months) } & Local review & 5.9 & 7.8 & 8.5 \\
\hline & Central review & NA & 11.0 & NA \\
\hline \multirow{2}{*}{$\begin{array}{l}\text { Noninfectious } \\
\text { pneumonitis (\%) }\end{array}$} & All grades & 10 & 20 & 13 \\
\hline & $\geq$ grade 3 & 0 & 4 & 1 \\
\hline \multirow{2}{*}{ Hyperglycemia(\%) } & All grades & 21.4 & 16 & 9 \\
\hline & $\geq$ grade 3 & 1.4 & 6 & 4 \\
\hline \multirow{2}{*}{ Hyperlipidemia(\%) } & All grades & 10 & 14 & NA \\
\hline & $\geq$ grade 3 & 0 & 1 & NA \\
\hline
\end{tabular}

Abbreviations: PFS, progression-free survival, NA, Not available.

a Survival data from Yardley et al [17]. Safety data from Rugo et al [32].

${ }^{\mathrm{b}}$ Data from Noguchi et al [31].

\section{DISCUSSION}

The combination of everolimus and endocrine therapy has been recommended for postmenopausal HR+/HER2- breast cancer patients in NCCN guideline. However, the registering clinical trials of everolimus in breast cancer hasn't started yet in China. Little evidence exist regarding the effectiveness and safety of this combination in Chinese patients. This study reported the efficacy of everolimus based endocrine therapy in Chinese population for the first time. In this study of HR+/HER2metastatic breast cancer, everolimus combined with endocrine therapy led to a PFS of 5.9 months $(95 \% \mathrm{CI}$ 4.6-7.2). And the median OS was still not reached with a median follow up of 10.3 months. The combination of everolimus and endocrine therapy in the present study seems to be less efficient than that in BOLERO-2, which can be explained by many reasons. First, this is a realworld observational study. $82.7 \%$ patients had visceral metastasis, $60 \%$ of them had more than 3 metastatic
A

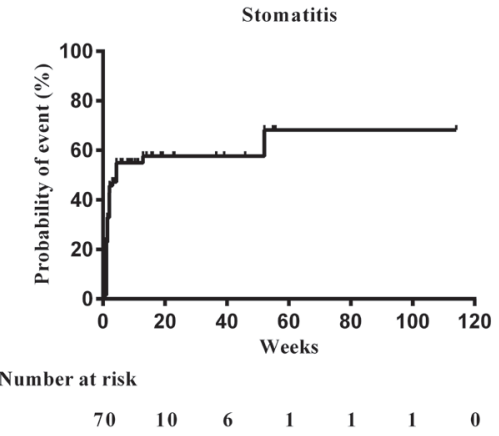

B

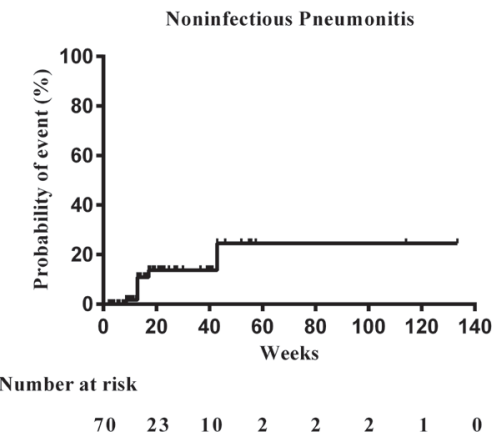

$\mathrm{C}$

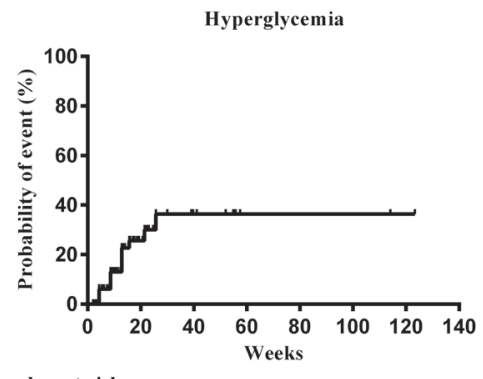

Number at risk

Figure 3: Cumulative risk estimates for initial onset of adverse events of clinical interest. A. Stomatitis. B. Noninfectious pneumonitis. C. Hyperglycemia. 
sites, and $77.3 \%$ had received chemotherapy in metastatic settings before everolimus while the corresponding percentage in BOLERO-2 was $58 \%, 35 \%$ and $26 \%$, respectively. The patients' characteristics in our study are consistent with findings from other real-world studies that oncologists tend to consider the addition of everolimus to endocrine therapy in patients with visceral metastasis, higher tumor burden, and in later lines of treatment [19, 20]. These discrepancies highlight the gap between randomized trials and real-world treatment. The latter indeed reveal more intricate clinical situations in real world, which always trouble clinicians. The results of our study may be a complement especially for those patients with multiple metastases. Second, besides exemestane, everolimus was also combined with anastrozole, letrozole, fulvestrant or tamoxifen in real-world practice. Although lacking robust evidence as BOLERO-2, these regimens have also been proved effective in different settings of clinical trials [21] [22] [14]. There is no direct comparison between these regimens. Exploratory analysis of our study shows that the PFS of everolimus was the longest when combined with exemestane (6.8 months), followed by tamoxifen (5.8months), anatrozole (4.8 months), letrozole (3.2 months) and fulvestrant (3.0 months), although no significant difference was reached. The relative superiority of these combinations still awaits further randomized clinical trials. Third, the median duration of everolimus exposure was only 15.1 weeks in our study, compared with 23.9 weeks in BOLERO-2, which might compromise the efficacy given that the duration of exposure is a surrogate marker for PFS. $14.4 \%$ of the discontinuations were up to patients' choice, mainly because of economic pressure. A cost-effective analysis based on the results of BOLERO-2 shows that the total cost of everolimus/exemestane $(\$ 63,584)$ was 21 times higher than the cost of exemestane alone $(\$ 3,010)$ [23]. Since everolimus hasn’t been covered up by Chinese health insurance, it makes sense that people might find it unable to afford.

Exploratory analyses also indicate that patients with symptomatic stomatitis had a significant longer PFS (7.8
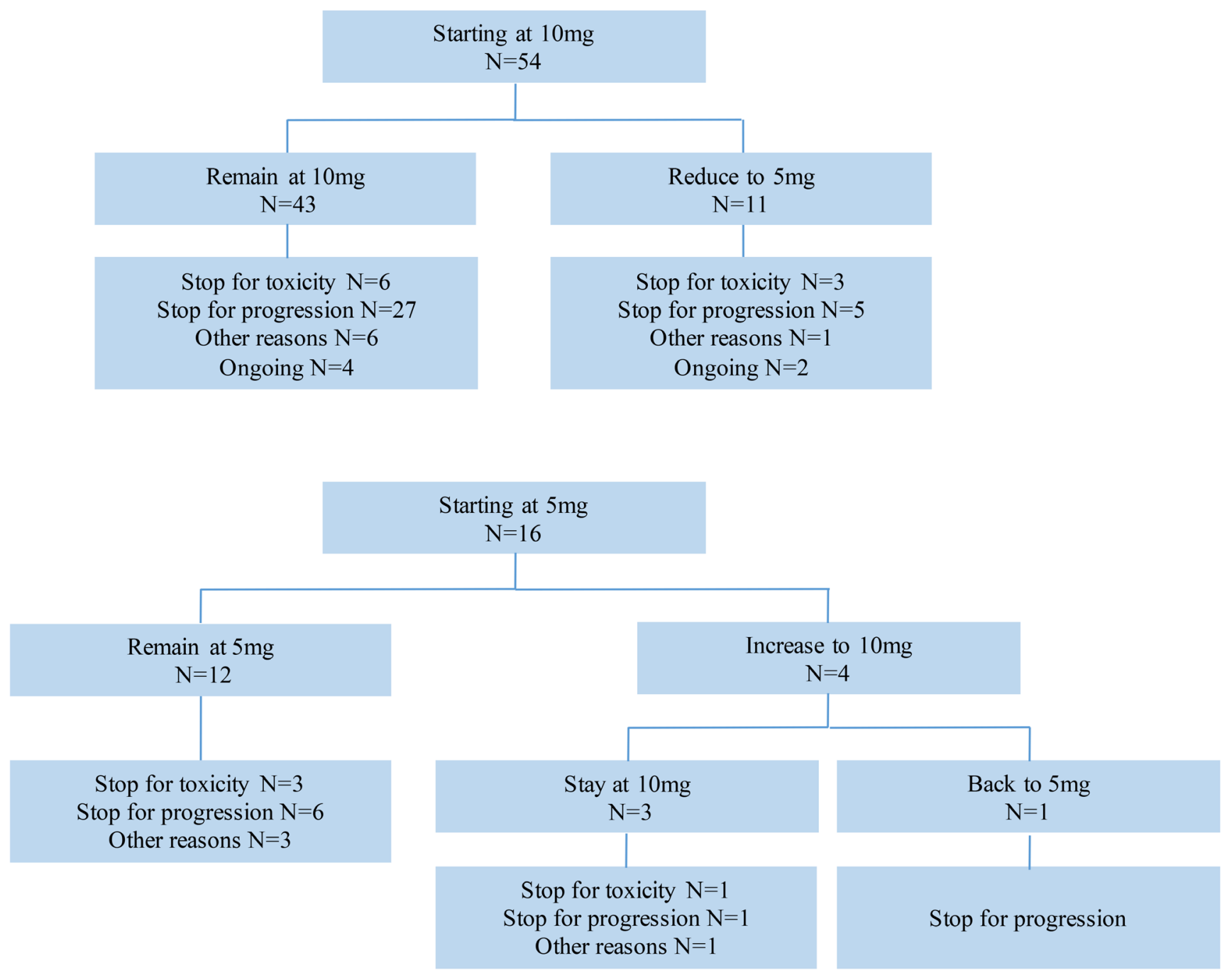

Figure 4: Dose pattern of everolimus. 
vs 4.8 months, HR, $0.57,95 \% \mathrm{CI} 0.34-0.98, p=0.042$ ). Stomatitis is a common adverse event associated with mTOR inhibitors. A meta-analysis of stomatitis incidence of everolimus and its relationship with efficacy included 7 randomized, phase III clinical trials conducted in patients with advanced breast cancer (BOLERO-2 and BOLERO3), renal cell carcinoma (RECORD-1), carcinoid tumors (RADIANT-2), and pancreatic neuroendocrine tumors (RADIANT- 3). The occurrence of stomatitis within 8 weeks of everolimus initiation was associated with longer PFS in BOLERO-2 (8.5 vs 6.9 months, HR, 0.78; 95\%CI 0.61-1.0), but not in BOLERO-3 studies [24]. The occurrence of specific AEs has been shown to predict better treatment responses both in target and endocrine therapy, such as rash induced by EGFR inhibitors [25, 26], hypertension after sunitinib treatment [27] and arthralgia/myalgia in exemestane treated patients [28]. Mechanism behind these correlations remains unclear. Unpleasant AEs, such as stomatitis or rash, could affect patients' compliance or lead to discontinuations, which would potentially compromise the efficacy of therapy. The contradictory influence of AE occurrence and dose reduction have on efficacy seem to be paradoxical. Further investigation is required. Howsoever, the potential correlation between symptomatic stomatitis and better efficacy will help improve adherence to everolimus and maximize treatment outcomes [29, 30].

In TAMRAD study, subgroup analysis shows that patients with secondary resistance seem to benefit more from the addition of everolimus than those with primary resistance (CBR in secondary resistance: $74 \%$ vs $48 \%$; $46 \%$ vs $36 \%$ in primary resistance) [14]. In our study, however, everolimus based therapy in patients with primary resistance seemed to be as effective as those with secondary resistance (PFS 5.1 vs 6.1 months, $p=0.530$ ).

Despite its striking PFS improvement, everolimus has also aroused many concerns about its toxicities, especially in Asian countries. Because the subgroup analysis of BELORO-2 shows that the incidences of mTOR inhibitor class-effect AEs, such as stomatitis, rash, and noninfectious pneumonitis, were higher among Asian patients [31]. It has become a major concern for oncologists and patients before considering the addition of everolimus in China.

In the present study, with the safety profile consistent with previous studies, the incidences of certain AEs were not as high as expected (Table 5). Stomatitis, the most frequent toxicity experienced with everolimus, is the leading reason for dose interruptions and reductions. In our study, the frequency of stomatitis was $57.1 \%$, similar with $67 \%$ in BOLERO-2 [32] and lower than $80 \%$ reported in Asian subgroup [31]. One possible reason for the difference was the duration of exposure to everolimus, which was 27.6 weeks in Asian subgroup and 15.1 weeks in our study. Another factor that may attribute to the decrease in stomatitis incidence is the prophylactic measures taken in our study. The prophylactic drugs used in clinical practice include kangfuxin solution and vitamin B group. Kangfuxin solution is a pure Chinese herbal medicine extracted from the American cockroach, and has been proved effective in preventing mucositis induced by chemoradiotherapy in a phase III clinical study of nasopharyngeal carcinoma [33]. Some oncologists also suggest encapsulating everolimus to avoid direct contact. Another study evaluating the effectiveness of these prophylactic measures in preventing the incidence and severity of stomatitis is ongoing in our center. The SWISH trial, recently reported at 2016 ASCO Annual Meeting, proved that the prophylactic use of steroid-based mouthwash markedly decreased the incidence and severity of stomatitis in MBC patients receiving eveolimus/ exemesatane, providing another cost-effective way of avoid the dose-limiting toxicity [34].

Noninfectious pneumonitis, a nonmalignant infiltration of the lungs associated with rapamycin derivatives, has a wide spectrum of disease severity varying from subclinical to fulminant, even fatal on rare occasions, therefore aroused many concerns. A recent meta-analysis of five clinical trials $(n=2233,989$ had breast cancer) [35] showed that the incidence of all-grade pneumonitis in everolimus $10 \mathrm{mg}$ recipients was $10.4 \%$, similar with $10 \%$ reported in our study. Among seven patients with the radiologic evidence of NIP, two patients presented with cough and dyspnea but soon resolved after everolimus discontinuation and short-term steroid therapy. The other five asymptomatic patients continued everolimus treatment. Follow-up CT and careful clinical assessment was performed. None of these patients showed any sign of deterioration.

Hyperglycemia and hyperlipidemia are of special interest because postmenopausal women already are at increased risk for age-related metabolic abnormalities. The incidence for all grade and $\geq 3$ hyperglycemia in our study was $21.4 \%$ and $1.4 \%$, compared with $16 \%$ and $6 \%$ in BOLERO-2 [32]. One limitation of this retrospective study was that not all patients had glucose data before the start of everolimus. Therefore, the incidence was highly likely to be overestimated. The incidence of hyperlipidemia was $10 \%$ in the present study, consistent with $14 \%$ reported in BOLERO-2 [32].

From the observations from our study, we can see that the AEs of everolimus are manageable, but require physician awareness, patient education and early intervention. Given the time course of everolimus related AEs observed in our study, we recommend a first followup visit in 2 weeks after starting everolimus, a laboratory test at least every 2 months, and a thoracic CT scan within 3 months.

This study is of importance for a number of reasons. First, it offers first-hand real-world data of the efficacy and safety of everolimus in combination with endocrine therapy in Chinese patients, which can be informative for 
clinical oncologists and provide supplementary data for the coming registration clinical trials in China. Second, exploratory analysis provides clues for the selection of patients who are likely to benefit more from the addition of everolimus. Last but not least, safety analysis of this study helps oncologists and patients to gain better knowledge and familiarization with possible side effects and when to expect them. Besides, adverse events of everolimus shown in this study are tolerable and predictable, which gives reassurance to patients who have concerns about toxicities.

This study was a retrospective study, therefore it was subject to limitations including potential missing data, possible recall and information bias and small sample size. Besides, it has been difficult to perform dose-effect analyses due to the complexity of treatment pattern and retrospective nature of this study. Furthermore, quality of life and time to resolution of AEs were not formerly assessed, which could have provided more comprehensive information on everolimus toxicities.

Future efforts to expand the therapeutic benefit of everolimus in patients with $\mathrm{HR}+$ breast cancer include investigating the introduction of everolimus in earlier settings (adjuvant study SWOG: NCT01674140 and UNIRAD: NCT01805271; first line therapy in BOLERO-4), or in different populations (NCT02313051: premenopausal women treated with goserelin after progressed on tamoxifen), or developing new combinations with other inhibition strategies (inhibitors of CDK4-6 (NCT02732119) or PI3K (NCT02077933). In addition, BRAWO, an ongoing large non-interventional study with a planned enrollment of 3000 patients will provide real-world data of everolimus plus exemestane in HR+/HER2- breast cancer. Taken together, we will be able to see the whole picture of the role everolimus plays in the treatment of HR+/ HER2- breast cancer.

\section{ACKNOWLEDGMENTS}

We appreciated the support of all participating patients and their families. We thank Yunhua Lu for telephone follow-up and Miaomo for statistical support.

\section{CONFLICTS OF INTEREST}

The authors have no conflict of interest to declare.

\section{GRANT SUPPORT}

This work was partially supported by National Natural Science Foundation of China (Grant No. 81302300) and Shanghai Natural Science Foundation of China (Grant No. 12ZR1406300).

\section{REFERENCES}

1. Setiawan VW, Monroe KR, Wilkens LR, Kolonel LN, Pike $\mathrm{MC}$, Henderson BE. Breast cancer risk factors defined by estrogen and progesterone receptor status: the multiethnic cohort study. Am J Epidemiol. 2009; 169: 1251-9. doi: 10.1093/aje/kwp036.

2. Chen W, Zheng R, Baade PD, Zhang S, Zeng H, Bray F, Jemal A, Yu XQ, He J. Cancer statistics in China, 2015. CA Cancer J Clin. 2016; 66: 115-32. doi: 10.3322/caac.21338.

3. Lim E, Metzger-Filho O, Winer EP. The natural history of hormone receptor-positive breast cancer. Oncology (Williston Park). 2012; 26: 688-94, 96.

4. Burstein HJ, Prestrud AA, Seidenfeld J, Anderson H, Buchholz TA, Davidson NE, Gelmon KE, Giordano SH, Hudis CA, Malin J, Mamounas EP, Rowden D, Solky AJ, et al. American Society of Clinical Oncology clinical practice guideline: update on adjuvant endocrine therapy for women with hormone receptor-positive breast cancer. J Clin Oncol. 2010; 28: 3784-96. doi: 10.1200/JCO.2009.26.3756.

5. Gradishar WJ, Anderson BO, Balassanian R, Blair SL, Burstein HJ, Cyr A, Elias AD, Farrar WB, Forero A, Giordano SH, Goetz M, Goldstein LJ, Hudis CA, et al. Invasive Breast Cancer Version 1.2016, NCCN Clinical Practice Guidelines in Oncology. J Natl Compr Canc Netw. 2016; 14: 324-54.

6. Ring A, Dowsett M. Mechanisms of tamoxifen resistance. Endocr Relat Cancer. 2004; 11: 643-58. doi: 10.1677/ erc. 1.00776 .

7. Miller TW, Hennessy BT, Gonzalez-Angulo AM, Fox EM, Mills GB, Chen H, Higham C, Garcia-Echeverria C, Shyr Y, Arteaga CL. Hyperactivation of phosphatidylinositol-3 kinase promotes escape from hormone dependence in estrogen receptor-positive human breast cancer. J Clin Invest. 2010; 120: 2406-13. doi: 10.1172/JCI41680.

8. Miller TW, Balko JM, Arteaga CL. Phosphatidylinositol 3-kinase and antiestrogen resistance in breast cancer. J Clin Oncol. 2011; 29: 4452-61. doi: 10.1200/JCO.2010.34.4879.

9. deGraffenried LA, Friedrichs WE, Russell DH, Donzis EJ, Middleton AK, Silva JM, Roth RA, Hidalgo M. Inhibition of mTOR activity restores tamoxifen response in breast cancer cells with aberrant Akt Activity. Clin Cancer Res. 2004; 10: 8059-67. doi: 10.1158/1078-0432.CCR-04-0035.

10. Beeram M, Tan QT, Tekmal RR, Russell D, Middleton A, DeGraffenried LA. Akt-induced endocrine therapy resistance is reversed by inhibition of mTOR signaling. Ann Oncol. 2007; 18: 1323-8. doi: 10.1093/annonc/mdm170.

11. Ghayad SE, Bieche I, Vendrell JA, Keime C, Lidereau R, Dumontet C, Cohen PA. mTOR inhibition reverses acquired endocrine therapy resistance of breast cancer cells at the cell proliferation and gene-expression levels. Cancer Sci. 2008; 99: 1992-2003. doi: 10.1111/j.1349-7006.2008.00955.x.

12. Boulay A, Rudloff J, Ye J, Zumstein-Mecker S, O'Reilly T, Evans DB, Chen S, Lane HA. Dual inhibition of mTOR 
and estrogen receptor signaling in vitro induces cell death in models of breast cancer. Clin Cancer Res. 2005; 11: 531928. doi: 10.1158/1078-0432.CCR-04-2402.

13. Awada A, Cardoso F, Fontaine C, Dirix L, De Greve J, Sotiriou C, Steinseifer J, Wouters C, Tanaka C, Zoellner U, Tang P, Piccart M. The oral mTOR inhibitor RAD001 (everolimus) in combination with letrozole in patients with advanced breast cancer: results of a phase I study with pharmacokinetics. Eur J Cancer. 2008; 44: 84-91. doi: 10.1016/j.ejca.2007.10.003.

14. Bachelot T, Bourgier C, Cropet C, Ray-Coquard I, Ferrero JM, Freyer G, Abadie-Lacourtoisie S, Eymard JC, Debled M, Spaeth D, Legouffe E, Allouache D, El Kouri C, et al. Randomized phase II trial of everolimus in combination with tamoxifen in patients with hormone receptor-positive, human epidermal growth factor receptor 2-negative metastatic breast cancer with prior exposure to aromatase inhibitors: a GINECO study. J Clin Oncol. 2012; 30: 271824. doi: 10.1200/JCO.2011.39.0708.

15. Shaw RJ, Cantley LC. Ras, PI (3)K and mTOR signalling controls tumour cell growth. Nature. 2006; 441: 424-30. doi: 10.1038/nature04869.

16. Baselga J, Campone M, Piccart M, Burris HA, 3rd, Rugo HS, Sahmoud T, Noguchi S, Gnant M, Pritchard KI, Lebrun F, Beck JT, Ito Y, Yardley D, et al. Everolimus in postmenopausal hormone-receptor-positive advanced breast cancer. N Engl J Med. 2012; 366: 520-9. doi: 10.1056/ NEJMoa1 109653.

17. Yardley DA, Noguchi S, Pritchard KI, Burris HA, 3rd, Baselga J, Gnant M, Hortobagyi GN, Campone M, Pistilli B, Piccart M, Melichar B, Petrakova K, Arena FP, et al. Everolimus plus exemestane in postmenopausal patients with HR $(+)$ breast cancer: BOLERO-2 final progressionfree survival analysis. Adv Ther. 2013; 30: 870-84. doi: 10.1007/s12325-013-0060-1.

18. Cardoso F, Costa A, Norton L, Senkus E, Aapro M, Andre F, Barrios CH, Bergh J, Biganzoli L, Blackwell KL, Cardoso MJ, Cufer T, El Saghir N, et al. ESO-ESMO 2nd international consensus guidelines for advanced breast cancer (ABC2)dagger. Ann Oncol. 2014; 25: 1871-88. doi: 10.1093/annonc/mdu385.

19. Xie J, Hao Y, Li N, Lin PL, Ohashi E, Koo V, Signorovitch JE, Wu EQ, Yardley DA. Comparative effectiveness of everolimus-based therapy versus endocrine monotherapy among postmenopausal women with HR+/HER2- metastatic breast cancer: a retrospective chart review in community oncology practices in the US. Curr Med Res Opin. 2015; 31: 1095-103. doi: 10.1185/03007995.2015.1021906.

20. Li N, Hao Y, Xie J, Lin PL, Zhou Z, Zhong Y, Signorovitch JE, Wu EQ. Everolimus use and associated factors among post-menopausal women with hormonal receptor positive/ human epidermal growth factor receptor 2 negative metastatic breast cancer. Curr Med Res Opin. 2015; 31: 1573-82. doi: 10.1185/03007995.2015.1062358.
21. Baselga J, Semiglazov V, van Dam P, Manikhas A, Bellet M, Mayordomo J, Campone M, Kubista E, Greil R, Bianchi G, Steinseifer J, Molloy B, Tokaji E, et al. Phase II randomized study of neoadjuvant everolimus plus letrozole compared with placebo plus letrozole in patients with estrogen receptor-positive breast cancer. J Clin Oncol. 2009; 27: 2630-7. doi: 10.1200/JCO.2008.18.8391.

22. Massarweh S, Romond E, Black EP, Van Meter E, Shelton B, Kadamyan-Melkumian V, Stevens M, Elledge R. A phase II study of combined fulvestrant and everolimus in patients with metastatic estrogen receptor (ER)-positive breast cancer after aromatase inhibitor (AI) failure. Breast Cancer Res Treat. 2014; 143: 325-32. doi: 10.1007/s10549013-2810-9.

23. Diaby V, Adunlin G, Zeichner SB, Avancha K, Lopes G, Gluck S, Montero AJ. Cost-effectiveness analysis of everolimus plus exemestane versus exemestane alone for treatment of hormone receptor positive metastatic breast cancer. Breast Cancer Res Treat. 2014; 147: 433-41. doi: 10.1007/s10549-014-3042-3.

24. Rugo HS, Hortobagyi GN, Yao J, Pavel M, Ravaud A, Franz D, Ringeisen F, Gallo J, Rouyrre N, Anak O, Motzer R. Meta-analysis of stomatitis in clinical studies of everolimus: incidence and relationship with efficacy. Ann Oncol. 2016; 27: 519-25. doi: 10.1093/annonc/mdv595.

25. Perez-Soler R. Can rash associated with HER1/EGFR inhibition be used as a marker of treatment outcome? Oncology (Williston Park). 2003; 17: 23-8.

26. Perez-Soler R. Rash as a surrogate marker for efficacy of epidermal growth factor receptor inhibitors in lung cancer. Clin Lung Cancer. 2006; 8 Suppl 1: S7-14.

27. Rini BI, Cohen DP, Lu DR, Chen I, Hariharan S, Gore ME, Figlin RA, Baum MS, Motzer RJ. Hypertension as a biomarker of efficacy in patients with metastatic renal cell carcinoma treated with sunitinib. J Natl Cancer Inst. 2011; 103: 763-73. doi: 10.1093/jnci/djr128.

28. Hadji P, Kieback DG, Tams J, Hasenburg A, Ziller M. Correlation of treatment-emergent adverse events and clinical response to endocrine therapy in early breast cancer: a retrospective analysis of the German cohort of TEAM. Ann Oncol. 2012; 23: 2566-72. doi: 10.1093/ annonc/mds055.

29. Hadji P. Improving compliance and persistence to adjuvant tamoxifen and aromatase inhibitor therapy. Crit Rev Oncol Hematol. 2010; 73: 156-66. doi: 10.1016/j. critrevonc.2009.02.001.

30. Ziller V, Kalder M, Albert US, Holzhauer W, Ziller M, Wagner U, Hadji P. Adherence to adjuvant endocrine therapy in postmenopausal women with breast cancer. Ann Oncol. 2009; 20: 431-6. doi: 10.1093/annonc/mdn646.

31. Noguchi S, Masuda N, Iwata H, Mukai H, Horiguchi J, Puttawibul P, Srimuninnimit V, Tokuda Y, Kuroi K, Iwase H, Inaji H, Ohsumi S, Noh WC, et al. Efficacy of everolimus with exemestane versus exemestane alone in 
Asian patients with HER2-negative, hormone-receptorpositive breast cancer in BOLERO-2. Breast Cancer. 2014; 21: 703-14. doi: 10.1007/s12282-013-0444-8.

32. Rugo HS, Pritchard KI, Gnant M, Noguchi S, Piccart M, Hortobagyi G, Baselga J, Perez A, Geberth M, Csoszi T, Chouinard E, Srimuninnimit V, Puttawibul P, et al. Incidence and time course of everolimus-related adverse events in postmenopausal women with hormone receptorpositive advanced breast cancer: insights from BOLERO-2. Ann Oncol. 2014; 25: 808-15. doi: 10.1093/annonc/ mdu009.

33. Luo Y, Feng M, Fan Z, Zhu X, Jin F, Li R, Wu J, Yang X, Jiang Q, Bai H, Huang Y, Lang J. Effect of Kangfuxin Solution on Chemo/Radiotherapy-Induced Mucositis in Nasopharyngeal Carcinoma Patients: A Multicenter, Prospective Randomized Phase III Clinical Study. Evid Based Complement Alternat Med. 2016; 2016: 8692343. doi: 10.1155/2016/8692343.
34. Rugo HS, Beck JT, Glaspy JA, Peguero JA, Pluard TJ, Dhillon N, Hwang LC, Nangia CS, Mayer IA, Meiller TF, Chambers MS, Warsi G, Sweetman RW, et al. Prevention of everolimus/exemestane (EVE/EXE) stomatitis in postmenopausal (PM) women with hormone receptorpositive $(\mathrm{HR}+)$ metastatic breast cancer $(\mathrm{MBC})$ using a dexamethasone-based mouthwash (MW): Results of the SWISH trial. Journal of Clinical Oncology. 2016; 34: 189-. doi: doi:10.1200/jco.2016.34.26_suppl.189.

35. Iacovelli R, Palazzo A, Mezi S, Morano F, Naso G, Cortesi E. Incidence and risk of pulmonary toxicity in patients treated with mTOR inhibitors for malignancy. A metaanalysis of published trials. Acta Oncol. 2012; 51: 873-9. doi: 10.3109/0284186X.2012.705019. 